\title{
Distribution Property of Shear Strength Parameters of Q2 and Q3 Loess in Northwest China and Its Application in Reliability Analysis of Natural and Filled Slopes
}

\author{
Xueyan Wang $\mathbb{D},{ }^{1}$ Yi-li Yuan $\mathbb{D}^{\mathbb{C}},{ }^{2}$ Changming $\mathrm{Hu} \mathbb{D}^{\mathbb{C}},{ }^{2}$ and Yuan Mei $\mathbb{C}^{2}$ \\ ${ }^{1}$ School of Urban Planning and Municipal Engineering, Xi'an Polytechnic University, Xi'an, Shaanxi 710048, China \\ ${ }^{2}$ College of Civil Engineering, Xi'an University of Architecture and Technology, Xi'an, Shaanxi 710055, China \\ Correspondence should be addressed to Yi-li Yuan; yuan.xauat@qq.com
}

Received 18 December 2020; Revised 2 January 2021; Accepted 28 January 2021; Published 11 February 2021

Academic Editor: Song-He Wang

Copyright (C) 2021 Xueyan Wang et al. This is an open access article distributed under the Creative Commons Attribution License, which permits unrestricted use, distribution, and reproduction in any medium, provided the original work is properly cited.

\begin{abstract}
Geological materials have randomness in nature. Statistical analysis can help revealing the variation pattern of the material parameters and the reliability of the slope. In this paper, the probability distribution and variability of shear strength parameters of typical $Q_{2}$ and $Q_{3}$ loess in Northwest China were statistically analysed using the collected geological survey data in Yan an, Shaanxi Province. Resulting probability properties were applied to the reliability analysis for the natural and fill slope in loess area using the Monte Carlo Method. Finally, an optimization analysis was carried out for the fill slope in the background engineering project. Research results show that normal distribution and lognormal distribution can be used to describe the statistical properties of $c$ and $\varphi$ of $Q_{2}$ and $Q_{3}$ loess. Variance of $c$ is large while the variability of $\varphi$ is relatively small. The influence of the variability of $\varphi$ on the reliability index of loess natural slope is generally larger than that of $c$. On the contrary, influence of the variability of $c$ on the reliability index of the fill slope is generally greater than that of $\varphi$, which is related to the structural and uniformity of the soil. Finally, relation between slope height and minimum gradient coefficient is linear when the failure probability of fill slope is less than $10 \%$. Results in this study can be used as a reference for the slope design and construction for the cut and fill engineering in loess area.
\end{abstract}

\section{Introduction}

In the design and construction of slope engineering, shear strength parameters are the most important aspects affecting the engineering quality. Since shear strength parameters have a stochastic nature, stability of the slopes is also not deterministic [1]. Reliability analysis is the method to estimate the uncertainty of the slope failure, which takes the randomness and variability of input variables into consideration, and the calculated failure probability or reliability index is more reasonable than a single safety factor resulting from a stability analysis. In the reliability analysis of slope, probability distribution models for the strength parameters of soils directly affect the calculation results [2]. Therefore, appropriate probability distribution models and accurate distribution parameters are key to the accuracy of the analysis results. Probability distribution models for different type of soil differs greatly [3-5]. Because of the water sensitivity, collapsible loess tends to have a bigger uncertainty than other soils [6]. In China, loess is widely distributed in northwest area. And, there are many cut and fill engineering being constructed in the recent years [7-9]. Thus, the number of natural and fill loess slopes are rising rapidly. In engineering practice, due to the lack of engineering experience and design basis, loess landslide accidents occur frequently [10]. Therefore, the reliability analysis for loess slope stability is particularly important.

The distribution probability model and variability of soil strength parameters have great influence on the calculation results of reliability [2]. Many researchers and scholars believe that the normal distribution and logarithmic normal distribution can be used to describe most soils $[11,12]$. 
However, some research also shows that the probability distribution form of strength parameters of soils has certain difference according to yield criteria [13]. $c$ and $\varphi$ of some soil do not strictly obey normal distribution [13]. Cui [14] concluded that positively skewed distribution is more adequate for some soils. In recent years, the normal information diffusion principle has been gradually applied to the determination of probability distribution of strength parameters rock and soil, and its error is far less than that of normal distribution and lognormal distribution [15]. For a slope reliability analysis, many methods are available, such as stochastic finite element method [16, 17], response surface method [18], and Monte Carlo method [19]. With the development of computer calculate capability, the Monte Carlo method is increasingly used in the reliability simulation of slope [20-22]. Moreover, the influence of variability of loess strength parameters on slope reliability is also studied by some scholars $[10,23]$. Despite the above research results, research for the stochastic properties of the loess in northwest China is still needed because of the strong regional characteristics of soil.

In this paper, to study the probability distribution and variability of shear strength parameters of typical $Q_{2}$ and $Q_{3}$ loess in Northwest China, geological survey data were collected and statistically analysed from two cut and fill engineering project in Yan'an, Shaanxi Province, and LvLiang, Shanxi Province of China (Figure 1). Resulting probability properties were applied to the reliability analysis for the natural and fill slope in loess area using the Monte Carlo Method. Finally, an optimization analysis was carried out for the fill slope in the background engineering project. Results in this study can be used as a reference for the slope design and construction for similar cut and fill engineering in loess area.

\section{Probability Distribution Analysis for Loess}

According to the geological survey report and engineering design of the cut and fill engineering of Yan'an and LvLiang, seven typical natural slopes and five fill slopes are selected as the research objects. Natural slopes are mainly composed of $Q_{3}$ and $Q_{2}$ loess stratum; Q2 stratum is the main body of loess hills; Q3 stratum is distributed among top of loess hills. The filling material of the filling slope is mainly $Q_{3}$ and $Q_{2}$ loess that was excavated from the loess ridges and hills. Figures 2 and 3 and Table 1 show the typical form and basic parameters of the selected slopes.

The $Q_{2}$ and $Q_{3}$ undisturbed loess samples are collected from the typical collapsible loess distribution area in engineering area. Statistical analysis results are shown in Figures $4-7$. The basic parameters of the sampled soil are shown in Table 2.

The probability distribution of cohesion (c) and angle of friction $(\varphi)$ of $Q_{2}$ and $Q_{3}$ undisturbed loess in Northwest China is statistically analysed. Histogram and probability density curves are shown in Figure 3. K-S test was employed to verify the distribution hypothesis of the data. The test results are shown in Table 3. In Table 3, $D_{\max }$ represents the maximum absolute value of the subtraction between the

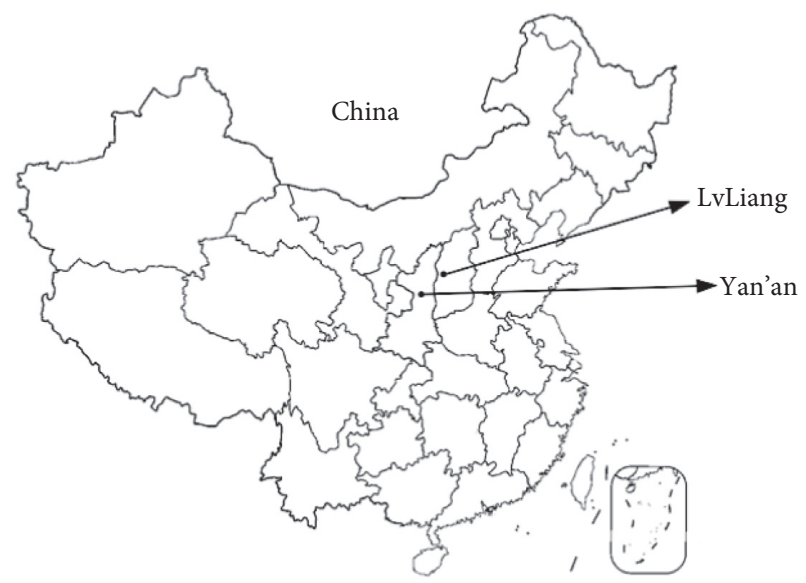

FIGURE 1: Engineering project locations.

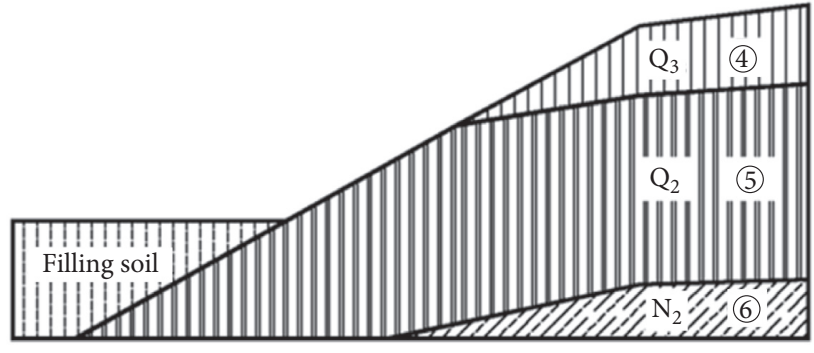

Figure 2: Typical natural slope.

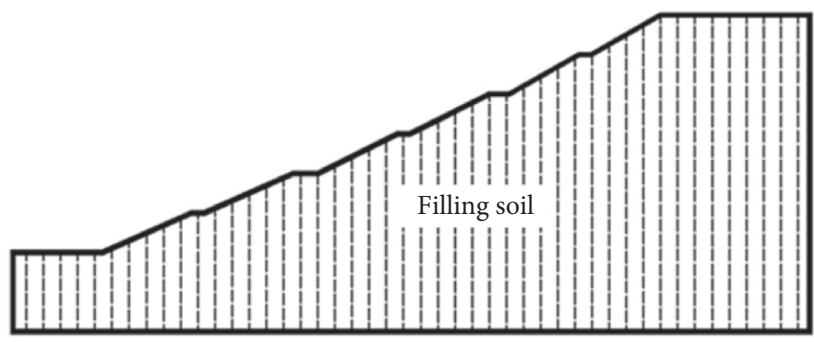

Figure 3: Typical fill slope.

empirical distribution function and the theoretical distribution function of the observation value. If $D_{\max }$ is less than the acceptable critical value $\mathrm{D}_{\mathrm{N}}{ }^{\alpha}$ (in which, $\alpha$ is the significance level and $n$ is the number of the sample data), it is reasonable to conclude that the sample data obey the corresponding distribution probability model. Otherwise, the hypothetical distribution probability model is not tenable and does not obey the suitable to represent the data. Test results show that the $c$ and $\varphi$ values of $Q_{2}$ and $Q_{3}$ obey both normal distribution and lognormal distribution.

\section{Variability Analysis of $c$ and $\varphi$}

By analysing the characteristics of the coefficient of variation of the strength parameters of loess in these areas, the variability of the parameters is studied. The coefficient of 
TABLE 1: The parameters of loess slopes.

\begin{tabular}{|c|c|c|c|c|c|c|c|c|c|c|c|c|}
\hline \multirow{2}{*}{$\begin{array}{l}\text { Slope type } \\
\text { Number }\end{array}$} & \multicolumn{7}{|c|}{ Natural slope } & \multicolumn{5}{|c|}{ Fill slope } \\
\hline & Z-1 & $\mathrm{Z}-2$ & Z-3 & $\mathrm{Z}-4$ & $\mathrm{Z}-5$ & Z-6 & $\mathrm{Z}-7$ & $\mathrm{~T}-1$ & $\mathrm{~T}-2$ & $\mathrm{~T}-3$ & $\mathrm{~T}-4$ & $\mathrm{~T}-5$ \\
\hline Slope height (m) & 32 & 46 & 57 & 77 & 100 & 110 & 119 & 20 & 32 & 40 & 48 & 56 \\
\hline Slope angle $/\left(^{\circ}\right)$ & 26.6 & 27 & 27 & 24.4 & 21 & 18.5 & 20.5 & 23 & 23 & 23 & 23 & 23 \\
\hline
\end{tabular}
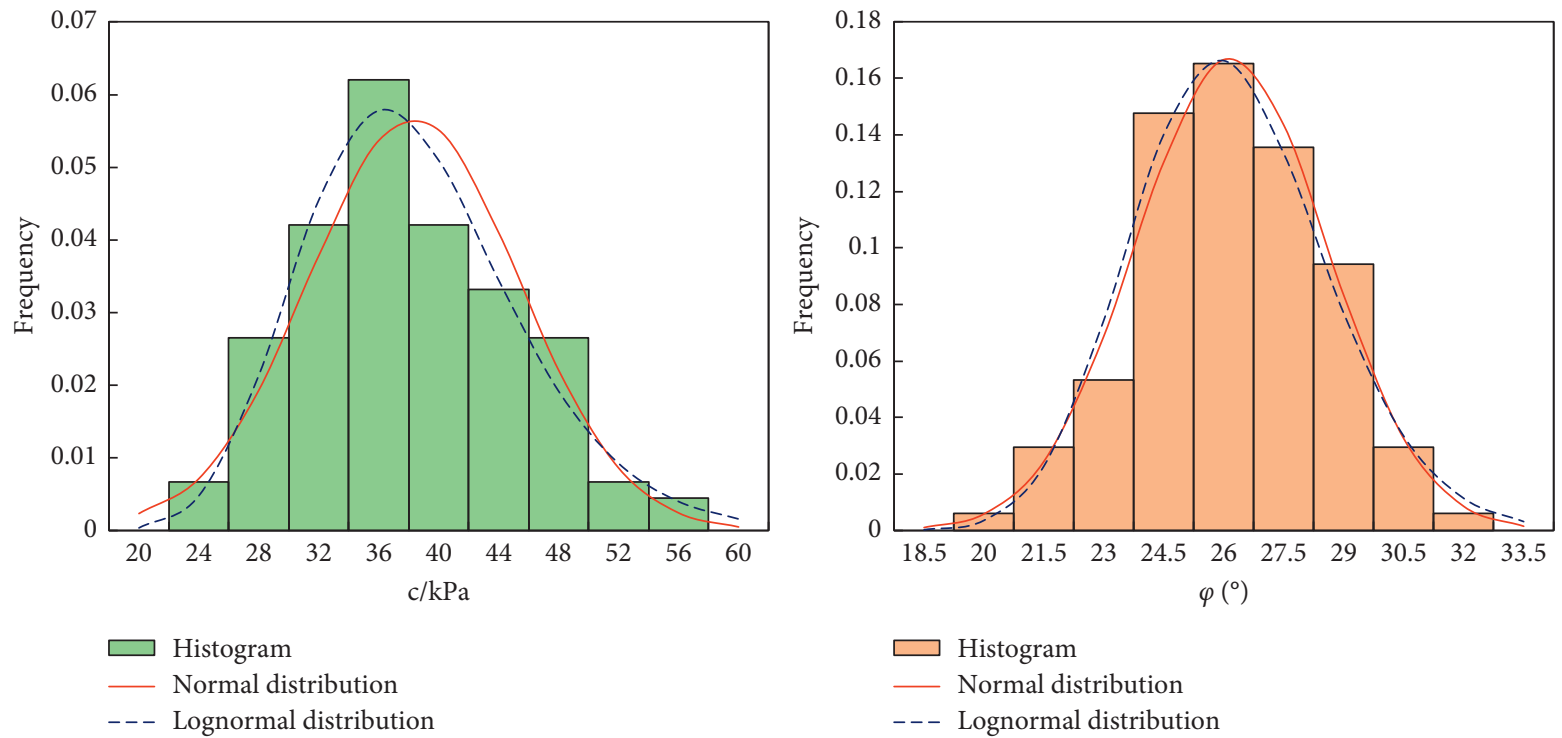

Figure 4: $Q_{2}$ undisturbed loess.
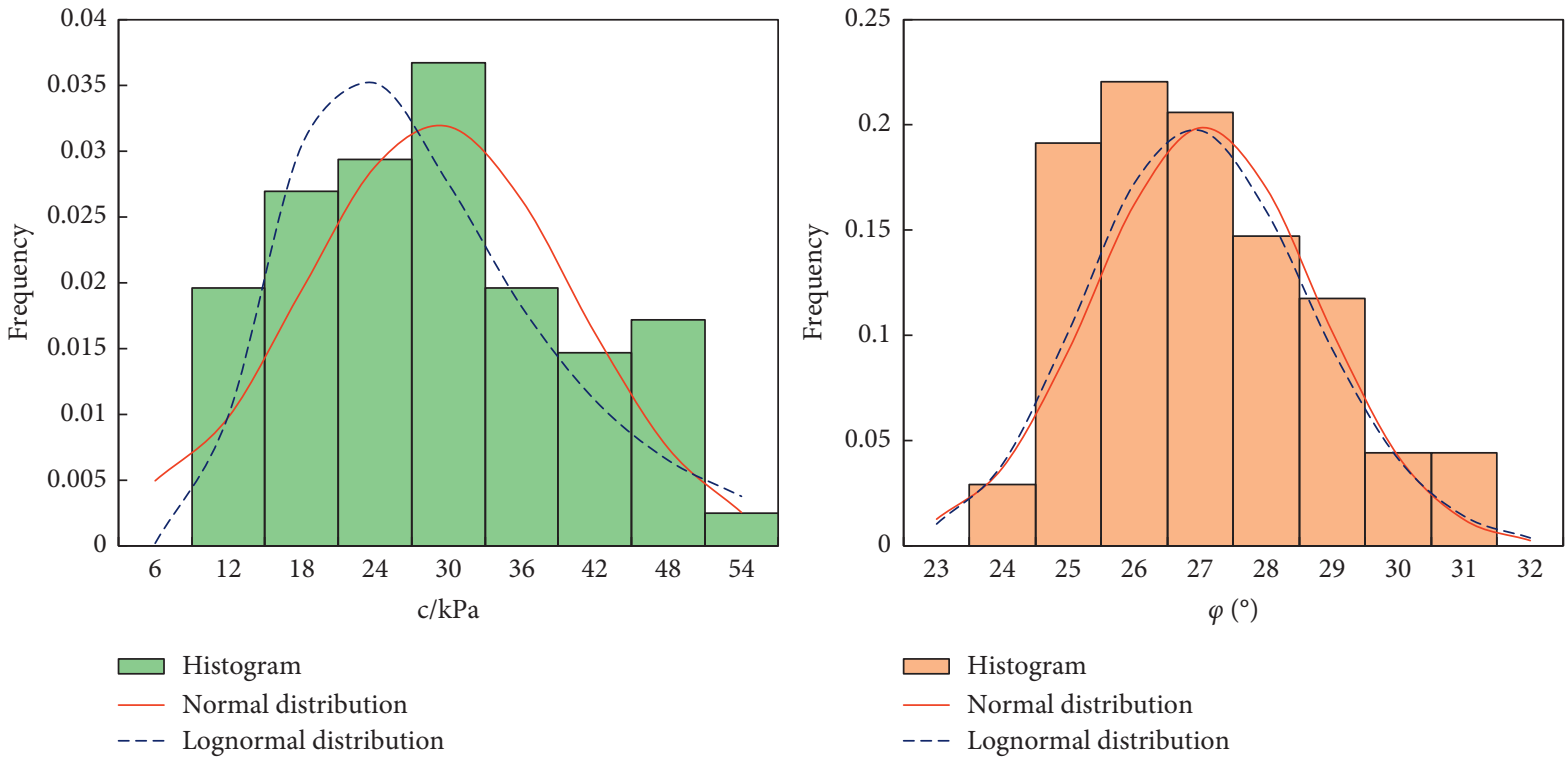

FIGURE 5: $Q_{3}$ undisturbed loess.

variation of each stratum is calculated separately according to the test type. The strength test mainly includes drained quick shear test, undrained quick shear test, and saturated undrained quick shear test. Since the statistical frequency of each stratum is different, the average value of coefficient of variation was calculated by weighted average method. There are 12 groups of data, as shown in Figure 8, in which the coefficient of variation of cohesion $(\mathrm{COV} c)$ ranges from 0.09 to 0.49 , which has a pretty large variability. Data dispersion of cohesion is large, the average coefficient of variation of 12 groups of is $0.25,30 \%$ of the data is greater than $0.35,38 \%$ of the data is greater than 0.25 , and $92 \%$ of the data is greater 

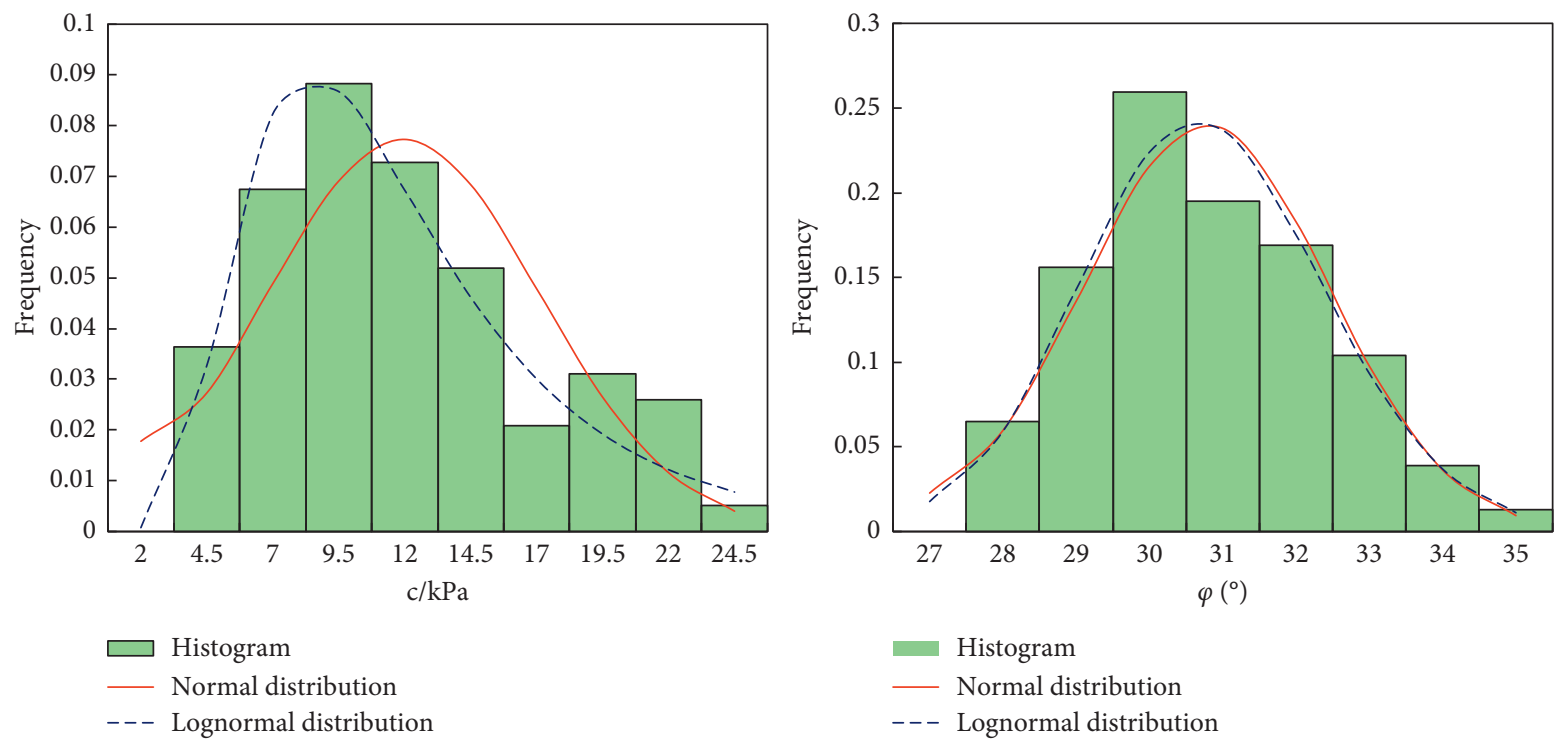

FIGURE 6: $Q_{2}$ disturbed loess.
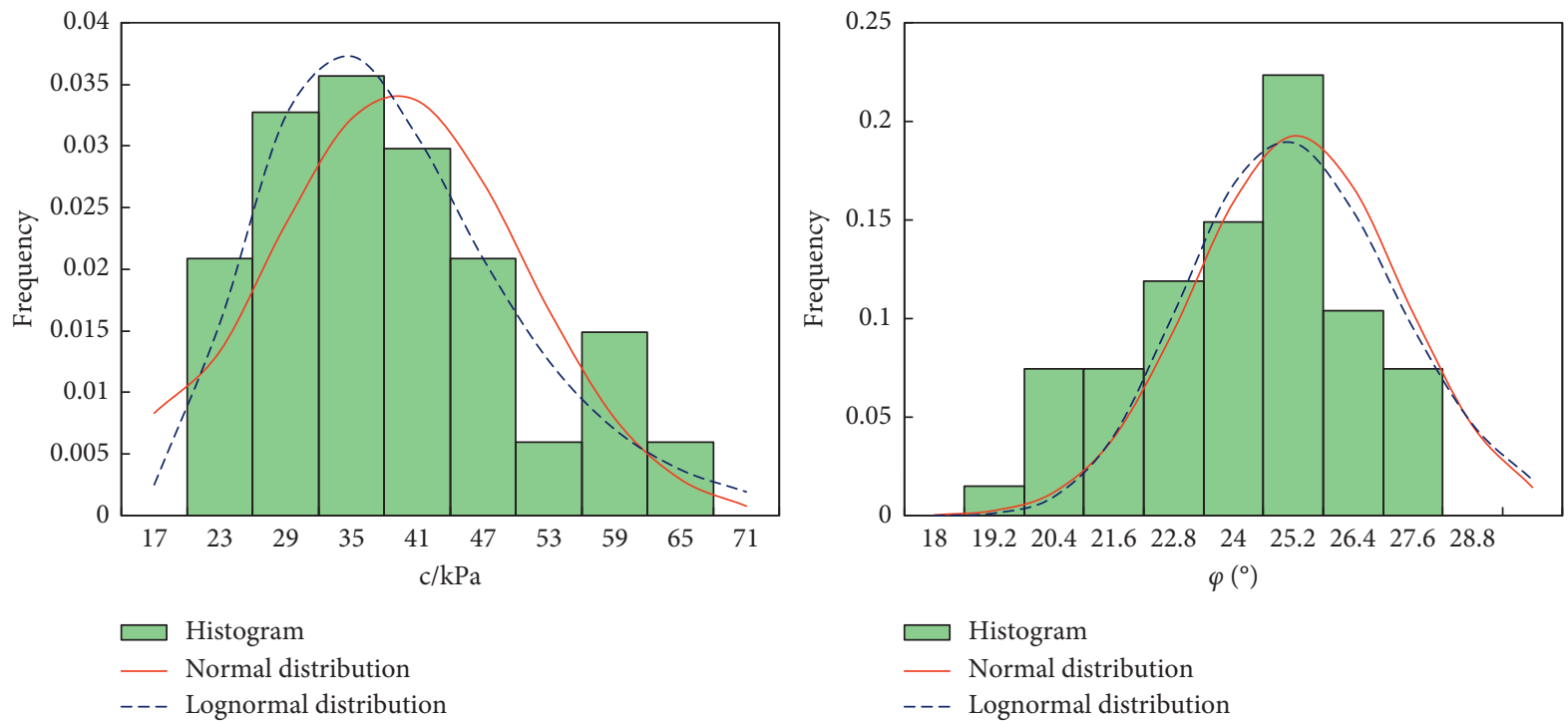

Figure 7: $Q_{3}$ disturbed loess.

TABLE 2: Statistical table of parameters of loess shear strength index.

\begin{tabular}{|c|c|c|c|c|c|c|c|}
\hline Strength parameters & Soil layers & Max. & Min. & Average & Standard variation & Coefficient of variation & Frequency \\
\hline \multirow{4}{*}{ Cohesion $c(\mathrm{kPa})$} & $Q_{3}$ (4) & 43 & 7 & 22.8 & 8.79 & 0.39 & 73 \\
\hline & $Q_{2}$ (5) & 49 & 21 & 35.7 & 6.62 & 0.19 & 116 \\
\hline & $\mathrm{N}_{2}$ (6) & 49 & 38 & 42.2 & 3.92 & 0.09 & 6 \\
\hline & Filling slope & 32 & 16 & 23.3 & 5.5 & 0.2 & 7 \\
\hline \multirow{4}{*}{ Angle of friction $\varphi\left({ }^{\circ}\right)$} & $Q_{3}$ (4) & 29.3 & 23.5 & 26.4 & 1.49 & 0.06 & 73 \\
\hline & $Q_{2}$ (5) & 29.9 & 20.6 & 25.5 & 2.11 & 0.08 & 116 \\
\hline & $\mathrm{N}_{2}$ (6) & 24.3 & 20.3 & 22.5 & 1.56 & 0.07 & 6 \\
\hline & Filling slope & 29.3 & 25.6 & 27.1 & 1.3 & 0.05 & 7 \\
\hline
\end{tabular}


TABLE 3: The results of distribution hypothesis test.

\begin{tabular}{|c|c|c|c|c|c|c|}
\hline \multirow{3}{*}{ Loess type } & \multicolumn{5}{|c|}{ Test results } & \multirow{3}{*}{ Acceptable threshold $\left(D_{n}^{\alpha}\right)(\alpha=0.05)$} \\
\hline & \multirow[t]{2}{*}{ Tested parameters } & \multicolumn{2}{|c|}{ Normal distribution } & \multicolumn{2}{|c|}{$\begin{array}{l}\text { Lognormal } \\
\text { distribution }\end{array}$} & \\
\hline & & Acceptance & $D_{\max }$ & Acceptance & $D_{\max }$ & \\
\hline \multirow{2}{*}{ Undisturbed $Q_{2}$} & $c$ & $\sqrt{ }$ & 0.069 & $\sqrt{ }$ & 0.080 & \multirow{2}{*}{0.1279} \\
\hline & $\varphi$ & $\sqrt{ }$ & 0.071 & $\sqrt{ }$ & 0.070 & \\
\hline \multirow{2}{*}{ Undisturbed $Q_{3}$} & $c$ & $\sqrt{ }$ & 0.097 & $\sqrt{ }$ & 0.092 & \multirow{2}{*}{0.1649} \\
\hline & $\varphi$ & $\sqrt{ }$ & 0.104 & $\sqrt{ }$ & 0.107 & \\
\hline \multirow{2}{*}{ Disturbed $Q_{2}$} & $c$ & $\sqrt{ }$ & 0.084 & $\sqrt{ }$ & 0.053 & \multirow{2}{*}{0.1550} \\
\hline & $\varphi$ & $\sqrt{ }$ & 0.100 & $\sqrt{ }$ & 0.096 & \\
\hline \multirow{2}{*}{ Disturbed $Q_{3}$} & $c$ & $\sqrt{ }$ & 0.102 & $\sqrt{ }$ & 0.113 & \multirow{2}{*}{0.1817} \\
\hline & $\varphi$ & $\sqrt{ }$ & 0.076 & $\sqrt{ }$ & 0.060 & \\
\hline
\end{tabular}

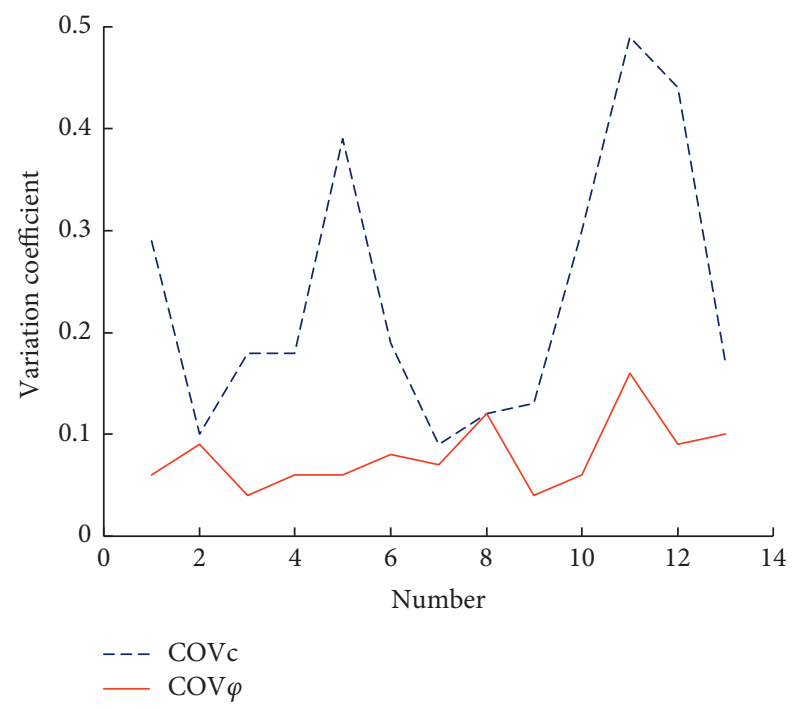

FIGURE 8: coefficient of variation of $c$ and $\varphi$ values.

than 0.1 . On the other hand, variability of $\varphi$ is rather small, the coefficient of variation of angle of friction $(C O V \varphi)$ ranges from 0.04 to 0.16 , the average value is $0.08,10 \%$ of the data is greater than $0.1,58 \%$ of the data is greater than $0.08,96 \%$ of the data is greater than 0.05 , and the dispersion is also small. Accordingly, the recommended standard values of $c$ and $\varphi$ are 0.3 and 0.1 , respectively. Considering the range of coefficient of variation in engineering and the recommended value from national standard, the combination of coefficient of variation of $c$ and $\varphi$ in Table 4 is adopted in this study.

\section{Reliability Analysis of Loess Slope}

4.1. Reliability Theory. The reliability of slope is usually expressed by failure probability $P_{f}$ or reliability index $\beta$ (Hu Changming et al., 2012). Failure probability $P_{f}$ and reliability $P_{r}$ complement with each other and obey the following relationship:

$$
P_{r}+P_{f}=1 .
$$

The slope stability is controlled by many factors (which can be referred to as state variables). Let the state variable be
TABLE 4: coefficient of variation combination of $c$ and $\varphi$ values.

\begin{tabular}{lcc}
\hline Combination & $\mathrm{COV} c$ & $\mathrm{COV} \varphi$ \\
\hline 1 & 0.1 & 0.1 \\
2 & 0.3 & 0.1 \\
3 & 0.5 & 0.1 \\
4 & 0.6 & 0.1 \\
5 & 0.3 & 0.05 \\
6 & 0.3 & 0.15 \\
7 & 0.3 & 0.2 \\
\hline
\end{tabular}

$X$, the resistance be $R$, and the load effect be $S$, the state function can be expressed as follows:

$$
Z=R(X)-S(X)=g\left(X_{1}, X_{2}, \ldots, X_{n}\right) .
$$

Function $\mathrm{g}(\mathrm{x})$ reflects the stable state of the slope and is determined by the state variable $X . X$ represents the main structural and environmental factor of the slope system, which is characterized by randomness and uncertainty. Limit state equation can be expressed as

$$
Z=R(X)-S(X)=g(X 1, X 2, \ldots, X n)=0 .
$$

Formula (3) represents a limit state surface in n-dimensional space, which divide the space into two regions: stable region $(z>0)$ and failure region $(Z<0)$. If $f_{R}(r)$ and $f_{S}(s)$ represent two probability density functions of two independent variable $R$ and $\mathrm{S}$, then $P_{f}$ can be calculated by

$$
P_{f}=\int_{-\infty}^{+\infty} f_{S}(s)\left[\int_{s}^{+\infty} f_{R}(r) \mathrm{d} r\right] \mathrm{d} s .
$$

Equation (4) can be solved by numerical integration, if $Z$ can be expressed explicitly, which is not possible for most circumstances. Therefore, the Monte Carlo method, firstorder second-moment method, JC method, and response surface method are often used. In this paper, the slope safety factor is solved by GeoStudio software, and the slope failure probability $P_{f}$ and reliability index $\beta$ are obtained using the Monte Carlo method. The reliability index $\beta$ is calculated by the following equation:

$$
\beta=\frac{(\mu-1)}{\sigma}
$$




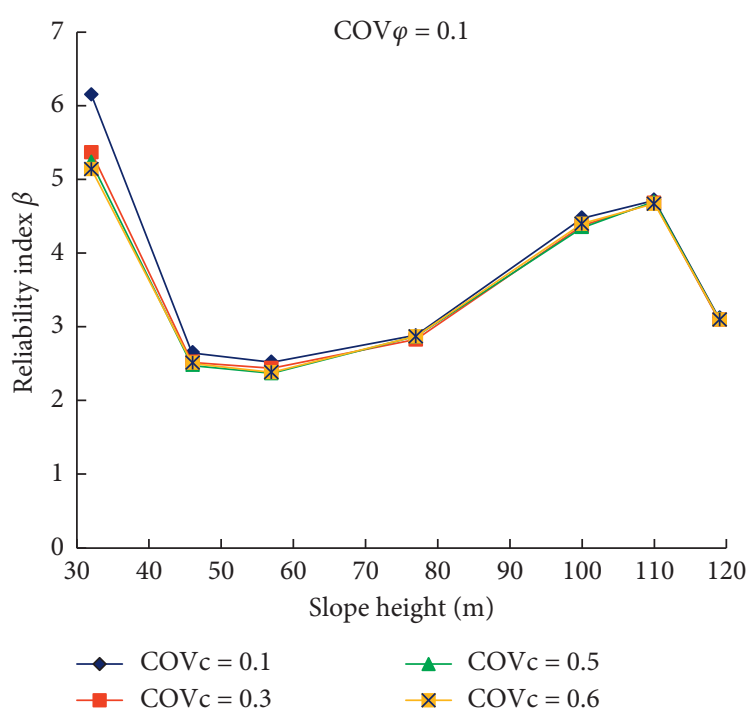

(a)

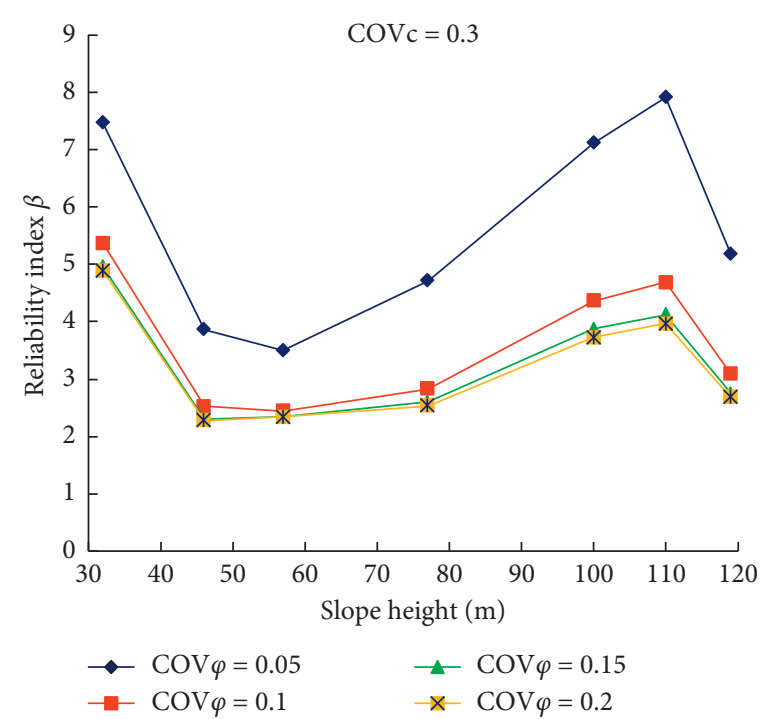

(b)

FIgURE 9: Reliability index of natural slope with different heights. (a) $\operatorname{COV}_{\varphi}=0.1$. (b) $\operatorname{COV}_{\varphi}=0.3$.
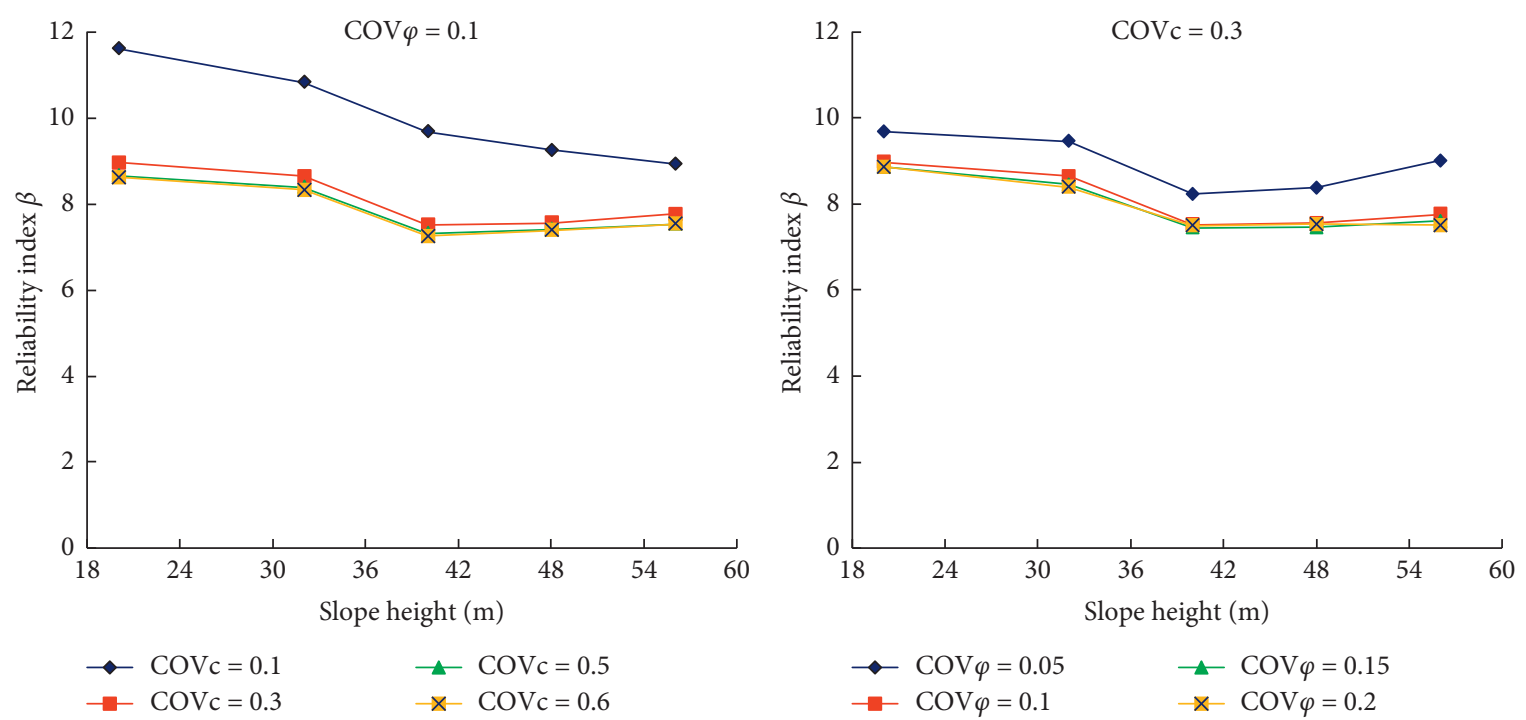

FIGURE 10: Reliability index of fill slope with different heights.

where $\mu$ is the average value of safety factor and $\sigma$ is the standard deviation of safety factor.

\subsection{Influence of the Variability of $c$ and $\varphi$ on Slope Reliability.} In order to calculate the reliability of slope, three soil parameters should be provided, i.e., natural unit weight $\gamma$, cohesion $c$, and internal friction angle $\varphi$. Since variability of the total weight of sliding mass is too small, only the variability of cohesion $c$ and internal friction angle $\varphi$ on slope reliability is considered. It can be seen from the above analysis results that both $c$ and $\varphi$ values obey normal distribution and lognormal distribution. And, considering the simplicity, normal distribution is preferred in reliability analysis.
To study the influence of variability of $c$ and $\varphi$ on the reliability of collapsible loess slope, numerical models were established based on 7 typical natural slopes and 5 filled slopes (Table 1 and Figure 2; Figure 3) in background engineering project. The reliability index $\beta$ of slopes under different combinations of coefficient of variation is analysed. The results are shown in Figures 9 and 10.

It can be seen from Figure 9 that the reliability indexes of the 7 natural slopes under different combinations of coefficient of variation are between 2.272 and 7.914, and the reliability indexes show an inverted S-shaped curve with the increase of slope height. Dispersion trend of the data under the same conditions shows that the influence of the variability of the value of $\varphi$ on the reliability index of the 
collapsible loess natural slope is generally greater than that of the $c$ value. It can be seen from Figure 9(a) that when the value of $C O V \varphi$ is kept constant, the influence of $C O V c$ on the reliability index of low slope is great, and when the slope height is higher (greater than $77 \mathrm{~m}$ ), the influence of $\mathrm{COVc}$ on the reliability index of high slope is small. It can also be seen from Figure 9(b) that when the COVc is kept constant, the impact of $C O V \varphi$ on the reliability index of the slope with slope height between $46 \mathrm{~m}$ and $77 \mathrm{~m}$ is small, and the impact of $\operatorname{COV} \varphi$ on the reliability index of lower or higher slope is greater.

It can be seen from Figure 10 that the reliability indexes of the 5 fill slopes under different combinations of coefficient of variation are between 7.261 and 11.615, and the reliability indexes show a downward trend with the increase of slope height. Dispersion trend of the data under the same conditions shows that when the value of $\operatorname{COV} \varphi$ is kept constant, the influence of $C O V c$ on the reliability index of low slope is great; and when the value of $C O V c$ is kept constant, the influence of $\operatorname{COV} \varphi$ on the reliability index of high slope is greater, which is contrary to that of natural slope. This may be related to the change of soil structure and uniformity, and its internal mechanism needs further study.

\section{Slope Ratio Optimization of Fill Slope}

The slope ratio is one of the most important factors affecting the stability of the slope and also affects the engineering quantity and cost of the slope [24]. Therefore, how to choose the slope ratio reasonably in engineering design is particularly important.

The slope ratio is the ratio of the vertical height of the slope to the projection length in the horizontal direction of the slope, expressed in the form of $1: m$, where $m$ is called the slope coefficient. According to the simulation results in this paper, the failure probability of five typical fill slope sections is approximately 0 when the slope ratio is $1: 2.35$ (i.e., the slope is $23^{\circ}$ ), which indicates that the slope is unlikely to fail. Therefore, the slope ratio is optimized based on the failure probability. The slopes with a height of $56 \mathrm{~m}, 48 \mathrm{~m}, 40 \mathrm{~m}$ and $32 \mathrm{~m}$ are selected for trial calculation. When $C O V c=0.2$ and $\operatorname{COV} \varphi=0.1$, the failure probability of four kinds of slopes under different slope ratios is shown in Figure 11.

It can be seen from Figure 11 that when the slope ratio is the same, the failure probability of the filling slope increases with the increase of the slope height; when the slope ratio is equal to $1: 2$, the failure probability of the four filling slopes is almost zero; when the slope ratio is equal to $1: 1.9$, the failure probability of the four filling slopes is less than $8.65 \%$; when the slope ratio is equal to $1: 1.85$, the failure probability of the filling slope with the slope height of $40 \mathrm{~m}$ and $32 \mathrm{~m}$ is less than $2.1 \%$; when the slope ratio is equal to $1: 1.8$, the failure probability of the four filling slopes is less than $2.1 \%$. The failure probability of filling slope with height of $40 \mathrm{~m}$ and $32 \mathrm{~m}$ is less than $0.84 \%$. Therefore, when the filling slope height is less than $40 \mathrm{~m}$, the slope ratio can be designed as 1 : 8 ; when the slope height is greater than $40 \mathrm{~m}$ and less than $56 \mathrm{~m}$, the slope ratio can be designed as $1: 1.9$; when the slope

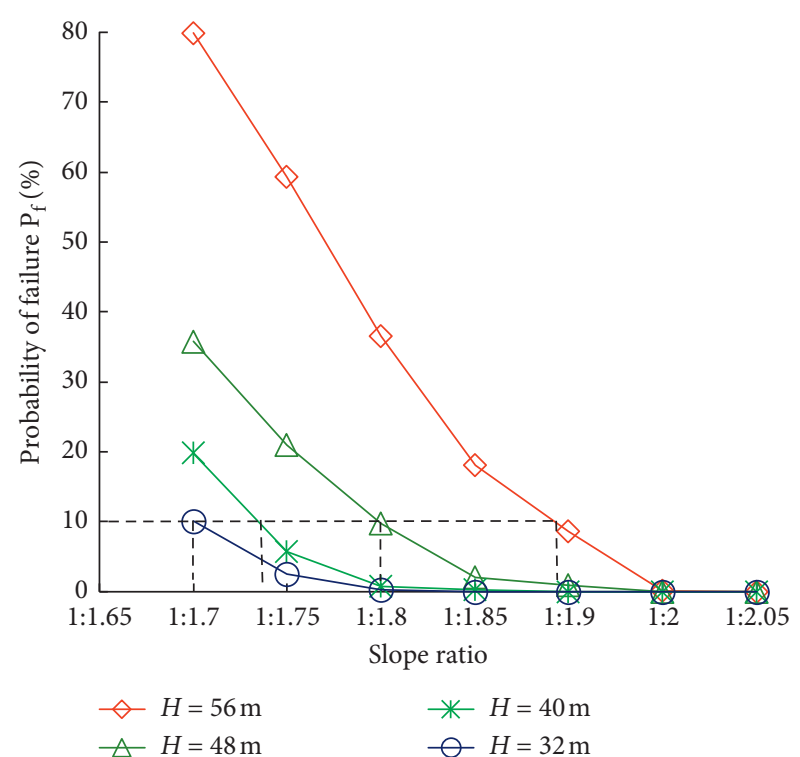

FIgURE 11: Probability of failure of different slope ratios.

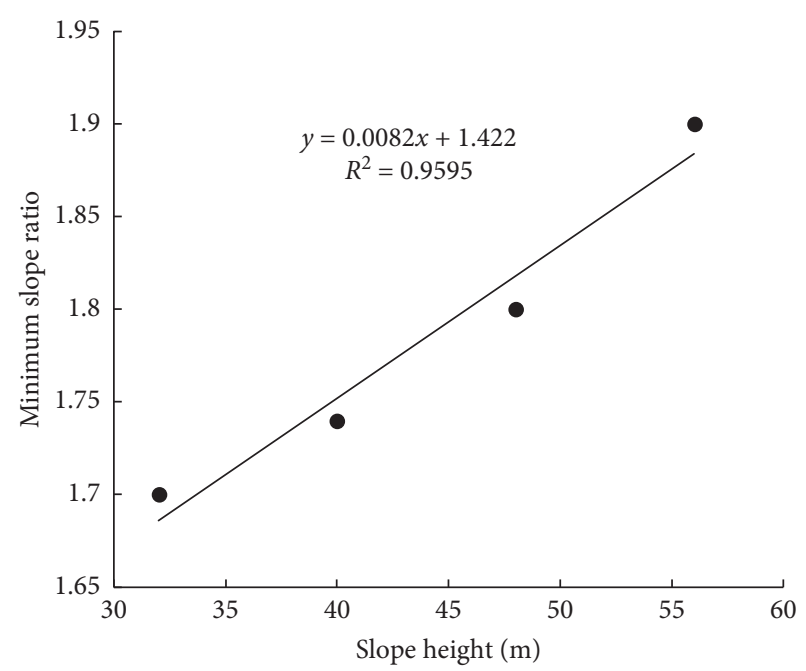

FIgURE 12: The relationship between slope height and the minimum slope ratio $\left(P_{\mathrm{f}}<10 \%\right)$.

height is greater than $56 \mathrm{~m}$, the slope ratio should be less than or equal to $1: 2$.

According to the above results, if the failure probability of the slope is required to be less than $10 \%$, the design slope rate of the slope should not be less than a certain slope coefficient. The relationship between the height of fill slope and the minimum slope coefficient is $y=0.0082 x+1.422$, as shown in Figure 12.

\section{Conclusion}

In this paper, the probability distribution and variability of shear strength parameters of typical $Q_{2}$ and $Q_{3}$ loess in Northwest China were statistically analysed using the collected geological survey data in Yan 'an, Shaanxi Province. Resulting probability properties were applied to the reliability analysis for the natural and fill slope in loess area 
using the Monte Carlo Method. Finally, an optimization analysis was carried out for the fill slope in the background engineering project. Several results can be concluded:

(1) Statistical analysis of different types of loess in northwest China was carried out in two cut and fill engineering project in Yan' an and LvLiang, and the $c$ and $\varphi$ values of $Q_{2}$ and $Q_{3}$ all obey normal distribution and lognormal distribution. The variability of $c$ value is larger than that of $\varphi$.

(2) The influence of the variability of angle of friction on the reliability index of natural collapsible loess slope is generally greater than that of cohesion. The influence of the variability of cohesion on the reliability index of fill collapsible loess slope is generally greater than that of angle of friction, on the other hand. These opposite conclusions may be related to the change of soil structure and uniformity, and its internal mechanism needs further study.

(3) If the failure probability of the slope is required to be less than $10 \%$, the design slope rate of the slope should not be less than a certain slope coefficient. The relationship between the height of fill slope and the minimum slope coefficient can be expressed as $y=0.0082 x+1.422$.

\section{Data Availability}

The data used to support the findings of this study are available from the first author upon request.

\section{Conflicts of Interest}

The authors declare that there are no conflicts of interest regarding the publication of this paper.

\section{Acknowledgments}

This work was supported by the Scientific Research Program funded by the Shaanxi Provincial Education Department (grant no. 19JK0381) and the Key Research and Development Project of Shaanxi Province (grant 533 no. 2020SF373).

\section{References}

[1] E. Sung, "Probabilistic assessment of slope stability that considers the spatial variability of soil properties," Journal of Geotechnical and Geoenvironmental Engineering, vol. 136, no. 7, pp. 975-984, 2010.

[2] X. B. Li and F. Q. Gong, "A method for fitting probability distributions to engineering properties of rock masses using Legendre orthogonal polynomials," Structural Safety, vol. 31, no. 4, pp. 335-343, 2009.

[3] Y. Wang, J. Liu, S. Yan, L. Yu, and K. Yin, "Estimation of probability distribution of shear strength of slip zone soils in Middle Jurassic red beds in Wanzhou of China," Landslides, vol. 14, no. 6, pp. 2165-2174, 2017.

[4] M. Yuan, Y.-L. Li, X.-Y. Wang, J. Wang, and C.-M. Hu, "Statistical analysis of deformation laws of deep foundation pits in collapsible loess," Arabian Journal for Science and Engineering, vol. 44, no. 10, pp. 8347-8360, 2019.

[5] T.-L. Tsai, T. Yu, P.-Y. Tsai, P.-J. Yang, and P.-J. Yang, "Probabilistic modeling of rainfall-induced shallow landslide using a point-estimate method," Environmental Earth Sciences, vol. 73, no. 8, pp. 4109-4117, 2015.

[6] C.-m. Hu, Y.-l. Yuan, Y. Mei, X.-y. Wang, and Z. Liu, "Comprehensive strength deterioration model of compacted loess exposed to drying-wetting cycles," Bulletin of Engineering Geology and the Environment, vol. 79, no. 1, pp. 383-398, 2020.

[7] M. Yuan, C.-M. Hu, Y.-L. Yuan, X.-Y. Wang, and N. Zhao, "Experimental study on deformation and strength property of compacted loess," Geomechanics \& Engineering, vol. 11, no. 1, pp. 161-175, 2016.

[8] J. Xu, J. Ren, Z. Wang, S. Wang, and J. Yuan, "Strength behaviors and meso-structural characters of loess after freezethaw," Cold Regions Science and Technology, vol. 148, pp. 104-120, 2018.

[9] J. Xu, Y. Li, W. Lan, and S. Wang, "Shear strength and damage mechanism of saline intact loess after freeze-thaw cycling," Cold Regions Science and Technology, vol. 164, Article ID 102779, 2019.

[10] J. S. Shi, L. Z. Wu, S. R. Wu, B. Li, T. Wang, and P. Xin, "Analysis of the causes of large-scale loess landslides in Baoji, China," Geomorphology, vol. 264, pp. 109-117, 2016.

[11] C. Jianye and K. Kok, "Modeling parameters of structured clays as a multivariate normal distribution," Canadian Geotechnical Journal, vol. 49, no. 5, pp. 522-545, 2012.

[12] V. I. Sheinin, "Use of the lognormal distribution for processing the results of mechanical testing of soils," Soil Mechanics and Foundation Engineering, vol. 57, no. 5, pp. 351-355, 2020.

[13] T. W. Schulz and S. Griffin, "Estimating risk assessment exposure point concentrations when the data are not normal or lognormal," Risk Analysis, vol. 19, no. 4, pp. 577-584, 1999.

[14] J. Cui, Q. Jiang, X. Feng, and, and H. Gao, "Theoretical probability distribution of shear strength parameters for rock," Rock and Soil Mechanics, vol. 36, pp. 1000-7598, 2015.

[15] H. Zhu, X. Li, and F. Gong, "Assessment of probability distribution of large samples of geotechnical parameters by using normal information spread estimation method," Rock and Soil Mechanics, vol. 36, pp. 1000-7598, 2015.

[16] S.-H. Jiang, D.-Q. Li, L.-M. Zhang, and C.-B. Zhou, "Slope reliability analysis considering spatially variable shear strength parameters using a non-intrusive stochastic finite element method," Engineering Geology, vol. 168, pp. 120-128, 2014.

[17] A. Johari and A. Talebi, "Stochastic analysis of rainfall-induced slope instability and steady-state seepage flow using random finite-element method," International Journal of Geomechanics, vol. 19, Article ID 040190858, 2019.

[18] L. F. Song, Y. Xiang, B. Xu, R. Pang, and Z. Y. Zhang, "3D slope reliability analysis based on the intelligent response surface methodology," Bulletin of engineering geology and the environment, 2020.

[19] D.-Q. Li, L. Wang, Z.-J. Cao, and X.-H. Qi, "Reliability analysis of unsaturated slope stability considering SWCC model selection and parameter uncertainties," Engineering Geology, vol. 260, Article ID 105207, 2019.

[20] A. Zhou, X. Huang, Na Li, P. Jiang, and W. Wang, "A Monte Carlo Approach to Estimate the Stability of Soil-Rock Slopes Considering the Non-Uniformity of Materials," SymmetryBasel, vol. 12, no. 5904, 2020. 
[21] J.-S. Cai, T.-C. J. Yeh, R.-X. Tang, R.-X. Tang, J.-C. Wen, S.-Y. Huang et al., "An adaptive sampling approach to reduce uncertainty in slope stability analysis," Landslides, vol. 15, no. 6, pp. 1193-1204, 2018.

[22] R. Halatchev and D. Gabeva, "Probabilistic analysis of seismic impact on open pit slope stability," International Journal of Mining, Reclamation and Environment, vol. 31, no. 3, pp. 167-186, 2017.

[23] P. Li, L. Huang, Z. Li, X. Li, and T. Li, "Study of reliability for loess high slopes in Gansu area," Rock and Soil Mechanics, vol. 34, pp. 1000-7598, 2013.

[24] M. He, Z. Zhang, J. Zheng, F. Chen, and L. Ning, "A new perspective on the constant mi of the Hoekâ $€$ "Brown failure criterion and a new model for determining the residual strength of rock," Rock Mechanics and Rock Engineering, 2020. 